\title{
NEGÓCIOS SOCIAIS: A PERCEPÇÃO, A CONSCIÊNCIA E O GRAU DE INTERESSE PELO TEMA PARA OS ALUNOS DE GRADUAÇÃO EM ADMINISTRAÇÃO
}

SOCIAL BUSINESS: PERCEPTION, AWARENESS AND

THE DEGREE OF INTEREST OF THE THEME FOR THE

UNDERGRADUATE STUDENTS IN BUSINESS ADMINISTRATION

\author{
Recebido em: 10/05/2016 • Aprovado em: 18/07/2016 \\ Avaliado pelo sistema double blind review \\ Editora Científica: Claudia Stadtlober \\ DOI 10.13058/raep.2016.v17n3.454
}

\section{AMANDA LEME JAHCHAN amanda.jahchan@gmail.com \\ GRAZIELLA MARIA COMINI \\ EDISON QUIRINO D'AMARIO}

FACULDADE DE ECONOMIA E ADMINISTRAÇÃO DA UNIVERSIDADE DE SÃO PAULO

\begin{abstract}
RESUMO
Este estudo teve como objetivo entender a percepção e o conhecimento dos alunos de administração da FEAUSP sobre o tema negócios sociais. Negócios Sociais são empreendimentos que alinham a lógica de mercado e a lógica social, ou seja, buscam a autossustentação pela venda de produtos e serviços juntamente com a geração de valor social. Considerou-se importante mapear até que ponto alunos de administração têm interesse nesse tipo de organização. Realizou-se um levantamento quantitativo com uma amostra de 515 alunos do curso de graduação em Administração de Empresas da FEA USP. Dentre os achados, destacaram-se: a maioria acredita que seu conhecimento é básico; tem alto interesse e acha importante; nunca participou de atividades extracurriculares; depende de recomendação de amigos e parentes para entender e fazer parte; não conhece o tema a fundo, mas faz muitas associações corretas de conceitos; e acredita que as maiores dificuldades dos empreendimentos sociais são autossustentação financeira e atração de investidores. A principal contribuição deste estudo está na observação que há uma lacuna no ensino de administração na formação de gestores para empreendimentos sociais. Palavras-chave: Negócios sociais. Conhecimento. Alunos de graduação.
\end{abstract}

\footnotetext{
ABSTRACT

This study aimed to understand the perception and knowledge that students from the FEA-USP hold on the theme of social business. Social enterprises are businesses that align market logic and social logic, i.e., seek self-sufficiency through the sale of products and services along with creating social value. It was considered important to identify the extent to which Business Administration students have interest in this type of organization. We made a quantitative survey with a sample of 515 Business Administration undergraduate students from the FEA-USP. Among the findings, we highlight: most of the students believe that their knowledge is basic; they have high interest and think it is important; they have never participated in extracurricular activities; they depend on the recommendation of friends and relatives to understand and take part; they don't know the subject in depth, but they make many correct associations between concepts; and they believe that the major difficulties of social enterprises are financial self-sufficiency and attracting investors. The main contribution of this study is on the observation that there is a gap in Business Administration teaching regarding the training of managers for social enterprises.

Keywords: Social business. Knowledge. Undergraduate students.
} 


\section{INTRODUÇÃO}

Com a globalização, barreiras geográficas e culturais foram estreitandose e a sociedade se viu em um contexto de integração de economias e políticas em todo o mundo (SOUSA, 20II). A maioria das empresas visa ao lucro e progresso e, para tanto, estrutura suas ações e estratégias para ganhar vantagens competitivas dentro de um mercado globalizado e com muitos concorrentes. Porter e Kramer (20II) afirmam que o capitalismo é um veículo inigualável para a satisfação das necessidades humanas, para o aumento da eficiência, a criação de empregos e a geração de riqueza. Porém essas consequências citadas por esses autores aconteceram de maneira desigual em todo o mundo e ajudaram a agravar a pobreza e a desigualdade social. De acordo com o Global Wealth Report (2014), do banco Credit Suisse, a parte inferior da pirâmide social possui menos de $\mathrm{I} \%$ da riqueza mundial e, em contraste, os mais ricos detêm $87 \%$ dessa riqueza. Além desses dados, de acordo com o Banco Mundial (2015), um em cada cinco latino-americanos tem sobrevivido com menos de 4 dólares por dia.

Pode-se sugerir, portanto, que não houve distribuição igual de bens e de riqueza, e que aqueles que ficaram com uma parcela quase que mínima sofrem em razão da falta de recursos, da fome, de problemas de saúde e do sistema de educação precário. Prahalad e Hart (2008) inferem que a base da pirâmide é composta por mais de dois bilhões de pessoas, ou seja, um sexto da humanidade que vive com menos de US\$1.500,00 por ano.

Nesse contexto, um movimento de filantropia cresceu entre os setores privados e acarretou o surgimento de muitas entidades sem fins lucrativos (COMINI; TEODÓSIO, 20I2). Empresas começaram a incorporar em suas próprias estratégias a responsabilidade social, e ONGs surgiram para resolver problemas sociais, econômicos ou ambientais.

Para citar exemplos, empresas de grande porte como Unilever e Natura planejam e executam projetos de cunho social e de responsabilidade ambiental para complementar suas estratégias. A primeira atua no Brasil "por meio de projetos aprovados por leis de incentivo fiscal; por meio do aporte direto de recursos por suas marcas, em linha com sua missão social; e 
pela Unilever Foundation, via parceiros globais que atuam em solo nacional"; e a segunda criou o Instituto Natura, que tem projetos que apoiam três pilares: Apoio na Gestão Pública da Educação, Inovações em Tecnologias Educacionais e Transformação Educacional e Social.

Por sua vez, ONGs como a Associação Comunitária Monte Azul e a Talentos do Capão surgiram para tentar amenizar problemas sociais por meio de arrecadação de doações. A Monte Azul é uma organização antroposófica, que beneficia mais de 5 mil famílias, promovendo o desenvolvimento humano. Já a ONG do Capão foi fundada, em 20I0, com o objetivo de tirar crianças das ruas, proporcionar treinos de natação, ballet, jiu-jitsu e descobrir talentos.

Porém esses dois tipos de organizações (ONGs e empresas tradicionais) se apresentam de formas opostas nos seus objetivos finais e, por isso, acabam sendo incompletos em termos de sanar os problemas da base da pirâmide: a empresa do setor privado focaliza nos resultados financeiros e na maximização do lucro; e as ONGs, no impacto social, dependendo de doações e com grande dificuldade em se manter financeiramente saudável.

Os negócios sociais surgiram, então, como meio-termo entre esses dois tipos de organizações, incorporando o melhor das duas: o negócio social é autossustentável financeiramente e centra-se no impacto social (COMINI; TEODÓSIO, 20I2).

Os negócios sociais não têm o objetivo de substituir instituições existentes como empresas convencionais, organizações sem fins lucrativos e agências públicas. Ao contrário, eles devem ser vistos como um "player" a mais que contribui fortemente para a inovação (BORZAGA; DEPEDRI; GALERA, 20I2).

A inovação social, definida por Phills, Deiglmeier e Miller (2008), é uma solução nova a um problema social, que é mais efetiva, sustentável ou justa que as soluções já existentes e para a qual os valores criados revertem principalmente à sociedade como um todo, e não apenas para indivíduos privados.

Os negócios com impactos sociais, apesar de novos em sua contextualização, têm o potencial de trazer uma resposta à forma como o capitalismo tradicional norte-americano vem sendo adotado, e as crises econômicas e financeiras atuais têm demonstrado que ele precisa ser revisto (BARKI; COMINI; AGUIAR, 20I5). 
Ao mesmo tempo que a globalização impulsionou o contato e a proximidade de pessoas e conhecimentos em todo o mundo, acredita-se que ela também exigiu que aqueles inseridos em determinados contextos históricos se adaptassem ao longo do tempo, devido ao surgimento de novos pensamentos e virtudes decorridos do avanço tecnológico e da internet.

O "boom" da tecnologia e internet influenciou o aparecimento de gerações distintas e dinâmicas, cada uma nascida e criada em épocas diferentes e influenciada por fatos históricos diferentes.

De acordo com Dries, Pepermans e Kerpel (2008), quatro gerações podem ser citadas: silenciosa, baby boomers, X e Y. A primeira contextualiza-se antes de 1945, tendo como principais valores a obediência, a lealdade e o idealismo; a segunda é da época de 1946 a 1964, onde a criatividade, a liberdade e o "workaholism" predominam; a terceira se engloba com os nascidos antes de I980 e tem como valores predominantes o individualismo, o materialismo e a flexibilidade; e a última, que é contextualizada em I98I até 200I, tem como valores a positividade, a paixão e o coletivismo.

A geração Y é cheia de expectativas, procura reconhecimento e sucesso pessoal. É estimado que mais de $60 \%$ dos jovens de 13 a 25 anos sentemse responsáveis por fazer a diferença no mundo, conforme aponta Alsop (2008). Ainda de acordo com o autor, ela é constantemente conectada com a tecnologia, aprecia diversidade, sofre de ansiedade, troca de emprego constantemente e tem o período de adolescência prolongado.

Ao verificar as características da geração $\mathrm{Y}$ e seu grande desejo de ser socialmente responsável, é possível identificar a representatividade de algumas escolas do Brasil em disseminar os negócios sociais. Universidades como a Fundação Getúlio Vargas e a Universidade de São Paulo apresentam práticas para incentivar o empreendedorismo social. Pode-se citar, nesse sentido, o Centro de Políticas Sociais, CPS/FGV, que busca contribuir para o desenvolvimento com equidade no Brasil mediante o estreitamento entre a pesquisa aplicada, o debate na sociedade e a implantação de políticas públicas; e o Centro de Empreendedorismo Social e Administração no Terceiro Setor, CEATS, que desenvolve projetos visando ao impacto social e à disseminação de conhecimento e práticas de gestão. 
Diante da importância do tema, o objetivo deste estudo foi analisar a percepção e consciência dos alunos de administração da Faculdade de Economia e Administração da Universidade de São Paulo, FEA-USP, sobre os Negócios Sociais e sua familiaridade com estes.

Buscou-se identificar o grau de conhecimento, o quanto esses jovens estão interessados e como eles se atualizam acerca do tema. Objetivou-se, também, verificar a facilidade ou dificuldade de se conseguir informações para aprimorar os conhecimentos sobre esse tipo de negócio.

Por fim, este estudo visou entender como os Negócios Sociais são conceituados e se existem confusões referentes às propriedades e definições na visão desses futuros administradores. 


\section{REFERENCIAL TEÓRICO}

\section{NEGÓCIOS SOCIAIS - SURGIMENTO E DEFINIÇÕES}

Não há uma situação exata ou um momento específico para o surgimento dos Negócios Sociais, visto que, em cada canto do mundo, algum movimento filantrópico surgiu para tentar mudar os paradigmas impostos até então. Cada lugar e sociedade pensava e continua pensando de maneira diferente, mas um aspecto era comum: os desafios de ordem social e ambiental resultantes do sistema econômico vigente eram inicialmente ignorados ou subestimados (ROSOLEN, 20I4).

Os esgotamentos de alguns recursos naturais e os agravamentos da desigualdade social começaram a chamar mais atenção, e as pessoas começaram a perceber que precisavam de uma alternativa dentro do próprio capitalismo. De acordo com Prahalad e Hart (2008), as empresas perceberam que há grande oportunidade na camada pobre da população, a chamada base da pirâmide, e que fazer investimentos nesta significa elevar bilhões de pessoas da pobreza e do desespero, evitando decadência social, caos políticos, terrorismo e colapso ambiental.

Fisher (2014) afirma que o surgimento da tendência de empreendedorismo social propiciou a emergência dos negócios socioambientais, que são empreendimentos que se caracterizam por seus propósitos sociais e/ou ambientais, com os quais buscam influenciar transformações econômicas e sociais.

O economista e vencedor do Prêmio Nobel da Paz, Muhammad Yunus, vivenciando todos os problemas da superpopulação de Bangladesh, criou o Grameen Bank para oferecer microcrédito para as camadas mais pobres do país. O "banco do povo" criou, ao longo dos anos, 27 organizações de cunho social, que englobam desde a maior empresa de telefonia do país até o fornecimento mais acessível financeiramente de assistência médica, trouxe discussões sobre o modo de se pensar das organizações tradicionais e impulsionou o desenvolvimento e destaque do conceito de Negócios Sociais (YUNUS; MOINGEON; LEHMANN-ORTEGA, 2009). 
Ao definir negócios sociais, é importante diferenciá-los de negócios tradicionais. Apesar de similares em alguns aspectos, esses dois tipos de organizações têm algumas diferenças (BARKI et al., 20I5).

A Social Enterprise Knowledge (SEKN), rede de colaboração composta pelas mais reconhecidas escolas de negócio ibero-americanas, define negócios sociais como organizações ou empresas que geram mudança social por meio de mecanismos de mercado. Isso inclui ONGs e organizações com fins lucrativos ou do setor privado envolvidas em atividades de negócios típicas do setor público, produzindo produtos e serviços de valor significativo (COMINI; BARKI; AGUIAR, 20I2).

Para Yunus (2007), existem dois tipos de negócios sociais: empresas cujos gestores focalizam mais em promover benefícios sociais do que em maximizar os lucros; e empresas que se centram em maximizar os lucros, mas são geridas por pessoas da camada mais pobre da sociedade.

De acordo com Yunus, Moingeon e Lehmann-Ortega (2009), os negócios sociais buscam compensar os custos de suas operações e têm direito de recuperar seus investimentos iniciais, porém focalizando no resultado social, e não no resultado financeiro, com o potencial de agir como agente de mudança no mundo.

Os negócios sociais guardam a característica de procurar inserir parcelas significativas de colaboradores/empregados, oriundas do próprio mercado de destino final, seja no processo produtivo ou na distribuição/venda do produto/serviço. Trata-se de um mecanismo de inclusão via consumo e geração de renda simultaneamente (SANTANA; SOUZA, 2015). De acordo com Dees (1998), para os empreendedores sociais, a missão social, explícita e central, e a geração de riqueza são modos de se criar valor, pois eles estão sujeitos à disciplina de mercado.

Esse novo tipo de negócio centrado no impacto social, conforme já ressaltado, surgiu como meio-termo entre organizações tradicionais e ONGs, dessa maneira, incorporando o melhor das duas: o negócio social é autossustentável financeiramente e focaliza-se no impacto social. 


\section{TERMINOLOGIA E PERSPECTIVAS}

Fischer (2014) assevera que o empreendedorismo social não é um fenômeno apenas brasileiro, nem mesmo típico de países de economia pouco desenvolvida; trata-se de uma tendência global que sinaliza para uma provável mudança das relações econômicas capitalistas.

Existem variações e terminologias para definir os negócios ou projetos que têm seu foco na inovação social, como "Negócio Inclusivo", "Empreendimento Social" e "Negócio Social", que podem ser usados dependendo de suas características e do modo de se alcançar o impacto social (COMINI; TEODÓSIO, 20I2).

De acordo com Comini, Barki e Aguiar (2012), três perspectivas sobre os negócios sociais podem ser apontadas: a europeia, a norte-americana e a dos países em desenvolvimento.

Na Europa, o conceito mais comum é de "Empreendimento Social", e seus objetivos tangem providenciar os serviços sociais e promover integração com grupos e comunidades necessitadas, seja na área urbana ou rural, agindo principalmente no campo educacional, cultural e ambiental.

Já na América do Norte, o termo mais conhecido é "Negócio Social", que inclui qualquer empreendimento que tenha em suas atividades e seu objetivo o impacto social, ao mesmo tempo que busque retornos financeiros.

Por fim, diferentemente das outras regiões, a perspectiva dos países em desenvolvimento tem como termo predominante os "Negócios Inclusivos", visando à redução da pobreza ao impacto social em longo prazo. No contexto brasileiro, o termo "Negócios Sociais" é mais conhecido e disseminado, apesar de o Brasil se encontrar nessa última perspectiva. É possível observar, portanto, que cada perspectiva tem seu termo mais comum dado às condições financeiras, econômicas e sociais de cada região.

Como exemplos de iniciativas no contexto brasileiro, destacam-se o Banco Pérola - banco que faz concessão de crédito para os mais necessitados, especialmente, jovens; a $4 \mathrm{YOU}_{2}$ - negócio social que ensina um novo idioma a preço acessível, com professores estrangeiros que buscam experiência transformadora; e a CDI - articula redes de lan houses comunitárias 
e agrega serviços de educação, financeiro, entretenimento, cultura e empreendedorismo.

Pode-se observar que existe um corpo crescente de jovens universitários compondo ou empreendendo nesses negócios sociais. Esses jovens mostramse engajados em negócios de impacto social no Brasil, como, por exemplo, o Movimento Choice - que tem como objetivo disseminar a discussão sobre esse tema nas universidades. Esses universitários, em sua maioria, pertencem à geração $\mathrm{Y}$, foco deste estudo.

\section{GERAÇÃO Y - DEFINIÇÃO E CARACTERÍSTICAS}

Para facilitar o estudo e prever tendências sociais e mercadológicas, autores e estudiosos do ramo de Gestão de Pessoas e/ ou Recursos Humanos separam toda a sociedade em grupos, com características parecidas e convergentes, chamados de gerações.

De acordo com Forkin (2003), uma geração designa um conjunto de pessoas que nasceram mais ou menos na mesma época e que foram modeladas conforme esta, por um mesmo tipo de influência educativa, política ou cultural, ou que vivenciaram e foram impressionadas pelos mesmos eventos.

Em convergência, uma geração é definida, de acordo com Kupperschmidt (2000), como um grupo identificável que compartilha ano de nascimento, idade a eventos significativos em estágios críticos de desenvolvimentos.

Atualmente, já existe outra geração sendo discutida, a dos nascidos depois de 200I, chamada geração $Z$, vivendo ainda mais a explosão da internet e das redes sociais, e o grande compartilhamento de ideias, opiniões, gostos e produtos.

A geração Y, foco deste estudo, é composta por jovens nascidos entre I98I e 200I, que hoje estão com idade entre 34 e I4 anos. De acordo com Dutra, Veloso e Nakata (2008), quando as pessoas da geração Y começaram a nascer, encontraram o Brasil passando por grande instabilidade econômica e, pouco depois, reinstalando a democracia. Esses fatos fizeram com que essas pessoas fossem diferentes da geração anterior, os baby boomers, em personalidade e em perfil profissional. 
Características gerais como ansiedade, paixão por tecnologia, ambição, impaciência e busca de reconhecimento definem a personalidade desses jovens, que estão imersos em um ambiente tecnológico (DUTRA; VELOSO; NAKATA, 2008). É muito comum encontrá-los andando pelas ruas, ouvindo música por Ipods ou $\mathrm{MP}_{3}$ s, lendo livros em Kindles e, principalmente, comunicando-se via smartphones.

Com relação ao mercado de trabalho e seus comportamentos, eles também guardam características diferentes - e mais intensas - das gerações anteriores. De acordo com Aprigio (2013), os jovens da geração Y são pessoas que valorizam a qualidade de vida e não o trabalho, são voltados para os resultados, buscam curtir a vida e estão posicionados contra a burocracia. Um exemplo que pode ser citado é o tempo de permanência em uma única empresa: os baby boomers costumavam ficar anos, já os da geração Y não têm essa intenção e estão sempre tentando trocar de emprego, carreira e áreas de estudo.

Com tantas diferenças nos comportamentos e focos de carreira, acabam acontecendo conflitos e choques de gerações. Veloso (2012) afirma que os mais velhos se sentem incomodados e, em certa medida, ameaçados pelos mais novos. Isso faz com que os gestores das empresas precisem estar preparados para lidar com essas diferenças e saber distribuir tarefas e atividades, dar e receber feedbacks, estar sempre alinhados com as tecnologias e entender que não é possível manter os Ys, por muito tempo, sem lhes oferecer desafios e troca de áreas e cargos.

Porém, apesar de os jovens dessa geração tenderem a ser mais egoístas, inquietos e lutarem por ser diferentes, eles também são inconformados e pretendem retribuir o que têm para a sociedade, transformando vidas e mudando o rumo da história. Mais de $60 \%$ dos jovens de I3 a 25 anos se dizem pessoalmente responsáveis por fazer a diferença no mundo e mais de $50 \%$ não trabalhariam em uma empresa que é socialmente irresponsável (ALSOP, 2008). 
METODOLOGIA

\section{CLASSIFICAÇÃO DA PESQUISA}

Quanto à forma de abordagem, a presente pesquisa é quantitativa. As pesquisas quantitativas, de acordo com Lakatos e Marconi (I985), têm como vantagens a possibilidade de conseguir informações mais precisas, podendo ser comprovadas, de imediato, as discordâncias; e permitir que os dados sejam quantificados e submetidos a tratamento estatístico.

Quanto aos objetivos, a presente pesquisa se enquadra em exploratória, pois, de acordo Lakatos e Marconi (1985), este tipo de pesquisa visa proporcionar maior familiaridade com o problema com vistas a torná-lo mais explícito. E quanto aos procedimentos técnicos, foi realizado um levantamento, pois envolve a interrogação direta das pessoas cujos comportamentos se deseja conhecer.

\section{AMOSTRA}

A amostra foi composta por 515 estudantes da faculdade de administração da FEA USP, de diferentes semestres e faixas etárias, para obter ampla abrangência de pensamentos, vivências e personalidades. Convém ressaltar que o curso de administração da FEA USP tinha r.059 alunos quando a pesquisa foi realizada. Portanto, a amostra foi composta por $48,63 \%$.

\section{INSTRUMENTO DE COLETA DE DADOS}

O instrumento é composto por 24 variáveis, entre elas, oito demográficas. As variáveis referentes ao grau de interesse por negócios sociais, percepção sobre o grau de interesses dos alunos da FEA, importância atribuída ao tema e grau de conhecimento foram mensuradas por questões do tipo Likert para verificar:

I. grau de conhecimento, interesse e importância: como esses jovens enxergam esses graus quanto a si próprios e aos colegas de classe;

2. realização de trabalho voluntário, participação em negócio social e presença do tema em alguma disciplina da faculdade; 
3. como eles se atualizam sobre o tema;

4. procura (ou não) de vagas nesse tipo de negócio;

5. motivos da procura (ou não) dessas vagas;

6. familiarização com movimentos estudantis e entidades;

7. maiores dificuldades na gestão de um negócio social;

8. critérios para um negócio ser definido como negócio social;

9. conhecimento sobre algum negócio social.

\section{MÉTODO DE ANÁLISE DE DADOS}

No emprego dos métodos quantitativos, de acordo com Gatti (2004), podese considerar que as boas análises dependem de boas perguntas que o pesquisador venha a fazer, ou seja, da qualidade teórica e da perspectiva epistêmica na abordagem do problema, que guiam as análises e as interpretações. Buscou-se apoio teórico para a elaboração do questionário e assim atender aos pressupostos do autor. Com relação ao posicionamento epistemológico, adotou-se um enfoque epistemológico positivista, que é mais presente nas abordagens empirista-positivista e hipotético-dedutiva, concluindo, portanto, que a necessidade de constatação empírica é muito presente nas pesquisas realizadas, mostrando a forte influência positivista no Programa de Graduação em Administração de Empresas da FEA USP.

Foram feitas análises estatísticas, utilizando-se programa SPSS Versão 20, de todos os dados coletados. O foco deu-se em análises descritivas, em que se pôde verificar as médias, as medianas, o desvio padrão e a frequência, além de tabelas de dados cruzados entre variáveis.

Adicionalmente, foram efetuados testes para verificar a normalidade da distribuição e testes de significância. Todos os testes indicaram distribuição normal e significância dentro dos padrões indicados por Hair et al. (2005).

Para as questões de escala métrica, foram realizados testes paramétricos uma vez que se observou, por meio das análises, que a distribuição era normal. Pelo fato de as variáveis métricas terem como objetivo verificar o grau de interesse, conhecimento e importância sobre Negócios Sociais, efetuou-se uma análise fatorial para verificar a possibilidade de redução de itens para as análises finais. 
Após várias realizações de análises fatoriais, a que mais se enquadrou na amostra foi com rotação Varimax e Componentes Principais. Os itens foram agrupados em um só fator que explicava 54,29\% da variância. Convém ressaltar que, antes de realizar a análise fatorial, foram efetuados os testes para verificar sua fatorabilidade, como tamanho da amostra, medida de adequação da amostra (Keiser-Mayer-Olkin - KMO), teste de esfericidade de Bartlett e matriz anti-imagem. 


\section{ANÁLISE DOS RESULTADOS}

A amostra inicial foi composta por 52I respondentes. Após a análise dos outliers, restaram $5 \mathrm{I} 5$ respondentes válidos. Mais da metade dos respondentes era do sexo masculino, sendo 4I,22\% do sexo feminino. Em relação à idade, a faixa etária predominante foi de 20 a 23 anos, representando $46,12 \%$ do total de respostas.

Observa-se que a maioria não estagia e não trabalha, representando $57,20 \%$ do total de respondentes. Obteve-se respondentes de todos os semestres, sendo que mais de $35 \%$ ainda estão no primeiro ano de faculdade. A menor porcentagem foi representada pelo terceiro ano (quinto ou sexto semestre). Vale destacar que a predominância de pessoas que não estagiam na amostra se deve à concentração de respostas nos dois primeiros anos de faculdade, pois, por regras estabelecidas, os alunos não têm permissão para começar a estagiar nesses períodos.

Por fim, mais de $90 \%$ dos respondentes não têm graduação anterior, sendo que apenas $43(8,25 \%)$ respondentes já são formados em outros cursos. Isso permite, portanto, conseguir avaliar melhor a influência da FEA USP no conhecimento dos alunos.

Quanto à participação em entidades, a porcentagem é bem equilibrada, sendo que um pouco mais da metade $(52,47 \%)$ faz parte de alguma entidade estudantil. Dentre as entidades citadas, destacaram-se a FEA Júnior USP, FEA Social, FEA Sport Business, Association Internationale des Etudiants em Sciences Economiques et Commerciales (Aiesec), que é um movimento que pretende engajar e desenvolver lideranças jovens para alcançar a paz mundial, Associação Atlética Acadêmica Visconde de Cairú (AAAVC), que é uma entidade que coordena as atividades esportivas da FEA/USP, Cursinho FEA USP, Liga do Mercado Financeiro, Programa de Extensão de Serviços à Comunidade (PESC), que tem como objetivos propiciar oportunidades para os alunos compartilharem com a sociedade os conhecimentos adquiridos e desenvolver a visão estratégica e empreendedora para a atuação social, Programa de Educação Tutorial (Pet Adm), que busca complementar a formação dos alunos da FEA/USP por meio de atividades de ensino, 
pesquisa e extensão, e FEA Consulting Club (FCC), que é uma entidade estudantil da FEA/USP e tem como objetivo aproximar os alunos da carreira de consultoria estratégica.

\section{GRAUS DE CONHECIMENTO, INTERESSE E IMPORTÂNCIA}

No tocante ao grau de conhecimento sobre negócios sociais, verificou-se que $72,46 \%$ dos respondentes afirmaram que têm conhecimento nulo ou básico e apenas i9 pessoas declararam que têm conhecimento avançado sobre o assunto.

A variável que mensura o grau de interesse teve 5I4 respondentes, média 3,7I, mediana 4 e moda também 4 . Houve predominância de respostas entre 3 e 4 , representando interesse médio. Convém ressaltar que se verificou mais pessoas respondendo que têm interesse altíssimo do que pessoas com interesse baixíssimo: apenas 27 pessoas responderam que não têm interesse no tema, e 44 responderam que têm alto grau de interesse.

Talvez, seja possível sugerir dois aspectos com base nessas observações: (I) se as pessoas fossem mais informadas, o interesse poderia ser maior; (2) o principal fator que gera interesse é o impacto social, e isso é sabido mesmo por quem define o próprio conhecimento como básico, então, aumentar o conhecimento não interfere no interesse.

Relativamente ao grau de interesse percebido dos alunos da FEA, foram obtidas 5I3 respostas, com média, moda e mediana iguais a 3. Infere-se que, por mais que o interesse dos alunos respondentes seja médio, a maioria deles $(69,78 \%)$ acredita que o interesse da FEA como um todo é baixo, atribuindo notas até 3 em uma escala em que i é baixíssimo e 6 é altíssimo.

Por fim, a última pergunta teve 509 respondentes, média 4,57 e mediana e moda 5. A grande maioria respondeu que considera o grau de importância alto, com 432 respostas, representando $84,37 \%$ do total. Apenas 5 pessoas responderam que não tem importância nenhuma.

Como os alunos colocaram que o tema é muito importante para a formação dos gestores, mas relataram que os alunos de administração não têm interesse, as conclusões que se podem tirar são que: eles não acreditam que os alunos entendam a importância e estão prejudicando, de certa maneira, sua própria graduação; ou não conseguem verificar nos colegas 
o interesse pelo tema, dado que é uma questão que depende muito da percepção própria.

Ao correlacionar essas quatro perguntas que remetem aos graus de conhecimento, interesse e importância ao semestre dos respondentes, podese ter um novo tipo de análise, como se elenca a seguir:

Tabela I Conhecimento dos respondentes versus semestre

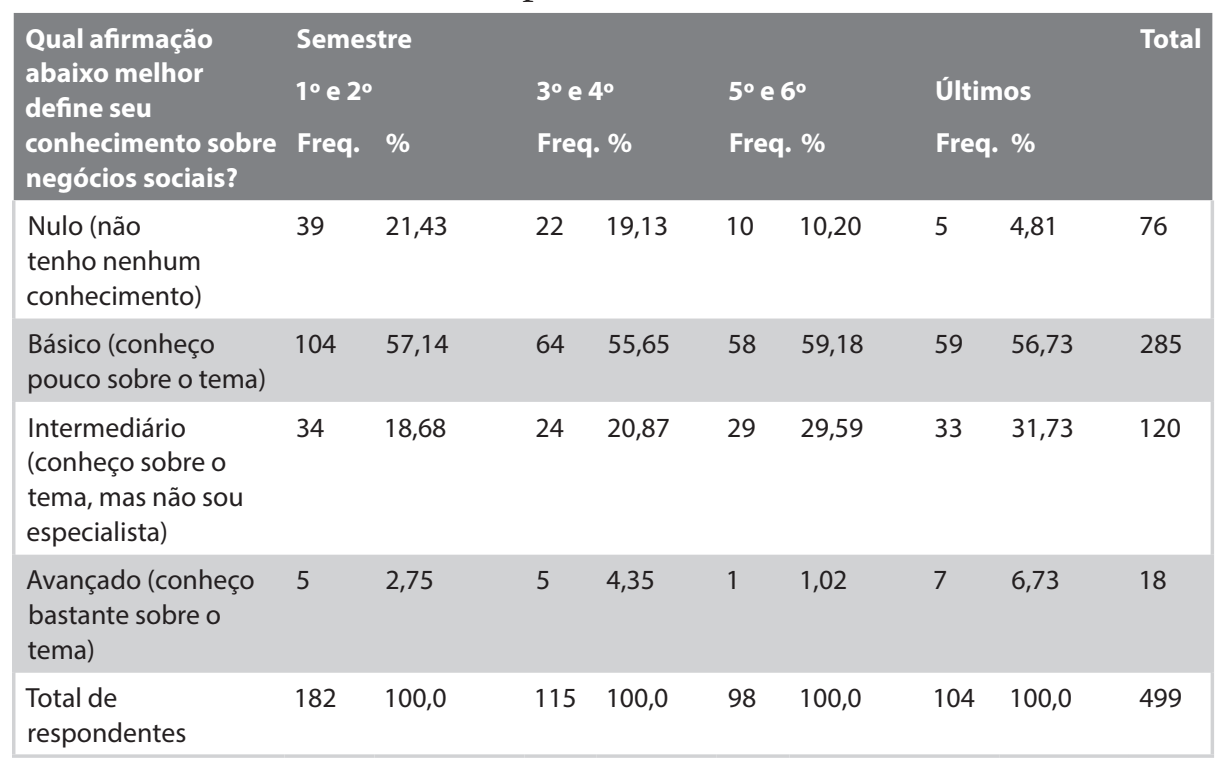

Na tabela r é possível observar que todos os semestres tiveram predominância de respostas que consideram o grau de conhecimento como básico, conhecendo, assim, pouco sobre o tema.

Pela análise de semestre por semestre, os alunos que têm conhecimento avançado ou intermediário estão, em sua maioria, nos últimos semestres da faculdade. E aqueles que responderam que seus conhecimentos eram nulos ou básicos estão nos primeiros anos, representando mais de $77 \%$ da amostra.

Pode-se sugerir, portanto, que à medida que os alunos vão passando de semestre a porcentagem dos que conhecem mais sobre o tema vai aumentando. Essa conclusão pode evidenciar a influência da graduação ou das experiências no mercado de trabalho. 
Tabela 2 Interesse dos respondentes versus semestre

\begin{tabular}{|c|c|c|c|c|c|c|c|c|c|}
\hline \multirow{3}{*}{$\begin{array}{l}\text { Como você } \\
\text { define o seu grau } \\
\text { de interesse no } \\
\text { tema negócios } \\
\text { sociais? }\end{array}$} & \multicolumn{8}{|c|}{ Semestre } & \multirow[t]{3}{*}{ Total } \\
\hline & \multicolumn{2}{|c|}{$1^{\circ}$ e $2^{\circ}$} & \multicolumn{2}{|l|}{$3^{\circ}$ e $4^{\circ}$} & \multicolumn{2}{|c|}{$5^{\circ}$ e $6^{\circ}$} & \multicolumn{2}{|c|}{ Últimos } & \\
\hline & Freq. & $\%$ & Freq. & $\%$ & Fre & $\%$ & Fre & $\%$ & \\
\hline 1 (baixíssimo) & 3 & 1,65 & 2 & 1,74 & 9 & 9,09 & 8 & 7,69 & 22 \\
\hline 2 & 48 & 26,37 & 33 & 28,70 & 25 & 25,25 & 29 & 27,88 & 135 \\
\hline 3 & 65 & 35,71 & 51 & 44,35 & 31 & 31,31 & 48 & 46,15 & 195 \\
\hline 4 & 51 & 28,02 & 25 & 21,74 & 24 & 24,24 & 17 & 16,35 & 117 \\
\hline 5 & 13 & 7,14 & 4 & 3,48 & 10 & 10,10 & 2 & 1,92 & 29 \\
\hline 6 (altíssimo) & 2 & 1,10 & 0 & 0,00 & 0 & 0,00 & 0 & 0,00 & 2 \\
\hline $\begin{array}{l}\text { Total de } \\
\text { respondentes }\end{array}$ & 182 & 100,0 & 115 & 100,0 & 99 & 100,0 & 104 & 100,0 & 500 \\
\hline
\end{tabular}

Na tabela 2, observa-se um equilíbrio entre os semestres, em que a maioria das respostas tange ao grau de interesse 2, 3 e 4, sendo baixo-médio. Nos últimos semestres, as porcentagens ficam concentradas em interesses de graus 2 e 3, com menos respostas no grau 4.

Pode-se observar que não se obteve nenhuma resposta considerando o grau de interesse altíssimo em alunos do terceiro semestre para frente e que os mais interessados pelo tema são os dos primeiros anos, respondendo graus de interesse 4, 5 ou 6. Esses alunos do primeiro ano, interessados no tema, representam mais de $35 \%$ da amostra, e pode-se sugerir que eles tenham adquirido esse interesse de situações vividas antes de entrarem na faculdade.

Temos um contraste ao comparar o grau de interesse e o de conhecimento: aqueles com mais tempo de graduação consideram o conhecimento maior, classificando entre intermediário e avançado, mas têm menos interesse pelo tema, classificando mais respostas nos graus 2 e 3 . Pode-se sugerir que o interesse é menor porque eles já sabem mais sobre o tema, ou isso é indício de que os alunos dos últimos semestres tendem a ter menos interesse, pois têm focos em carreiras diferentes, dado que eles já estão estagiando em outras áreas, por exemplo. 
Tabela 3 Importância para a formação versus semestre

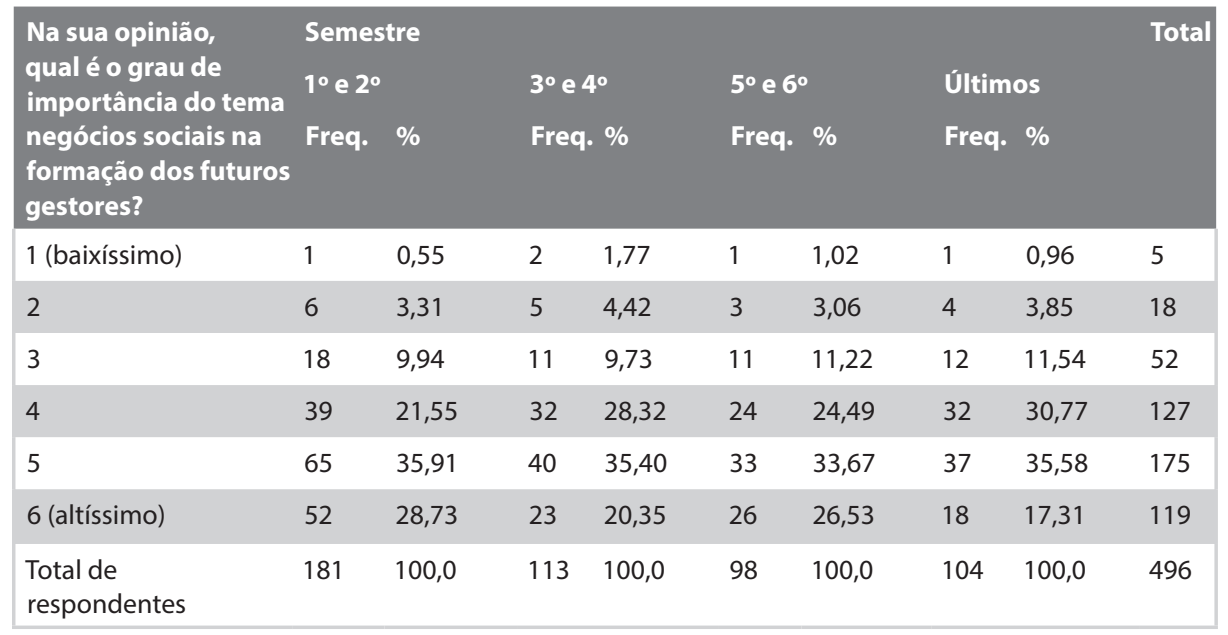

Na tabela 3 é possível observar que, em todos os semestres, a maioria dos respondentes apontaram que o grau de interesse está entre médio e altíssimo. Esses números são maiores a partir do terceiro ano, podendo-se sugerir que eles já estagiaram ou já tiveram alguma experiência no mercado de trabalho e perceberam a importância dos negócios sociais ou também pelo fato de terem tido a oportunidade de maior contato com o tema durante a graduação.

\section{ATIVIDADES EXTRACURRICULARES, DISCIPLINAS, PARTICIPAÇÃO EM NEGÓCIOS E TRABALHO VOLUNTÁRIO}

Os dados da pesquisa indicam que mais de $65 \%$ dos respondentes nunca fizeram uma atividade extracurricular sobre o tema. Aqueles que fizeram, citaram palestras, eventos da FEA júnior USP e FEA Social, resolução de casos e eventos da CHOICE, Ashoka e Yunus.

As respostas foram bem-divididas quanto ao trabalho voluntário, sendo que a maioria respondeu que já fez algum tipo de trabalho voluntário. Todavia muitas respostas tangiam a "entidades estudantis", "doação de dinheiro quando há catástrofes ambientais" e "participação em palestras", por exemplo. 
É possível fazer uma discussão sobre a percepção dos alunos ao participarem dessas atividades, dado que "o trabalho voluntário é definido pela Lei 9.608/1998 como a atividade não remunerada prestada por pessoa física a entidade pública de qualquer natureza, ou a instituição privada de fins não lucrativos, que tenha objetivos cívicos, culturais, educacionais, científicos, recreativos ou de assistência social, inclusive mutualidade". Essa definição pode fazer com que alunos acreditem que entidades estudantis sejam trabalhos voluntários, por exemplo, apesar de muitas vezes elas visarem ao lucro.

Mais de $93 \%$ nunca fizeram parte de um negócio social e mais de $86 \%$ afirmaram que não tiveram contato com o tema em nenhuma disciplina na FEA. Aqueles que tiveram, citaram a disciplina "Responsabilidade Social e Empreendedorismo Social", "Ciências Sociais" e "Introdução ao Direito".

Formas de Atualização

Neste item, consideraram-se apenas as respostas daqueles que têm grau de conhecimento intermediário ou avançado e aqueles com grau de interesse alto.

Tabela 4 Formas de Atualização

\begin{tabular}{|lll|}
\hline Grau de conhecimento intermediário ou avançado & & \\
\hline Formas de atualização & Frequência & Percentual \\
\hline Primeira opção - Amigos e/ou Parentes & 43 & $42,16 \%$ \\
\hline Segunda opção - Mídias Sociais & 26 & $25,49 \%$ \\
\hline Terceira opção - Jornais e Revistas & 23 & $22,55 \%$ \\
\hline Outros & 10 & $9,80 \%$ \\
\hline Total & 102 & $100,00 \%$ \\
\hline
\end{tabular}

\begin{tabular}{|lll|}
\hline Grau de interesse Alto ou Altíssimo (5 ou 6) & & \\
\hline Formas de atualização & Frequência & Percentual \\
\hline Primeira opção - Mídias Sociais & 47 & $43,12 \%$ \\
\hline Segunda opção - Amigos e/ou Parentes & 23 & $21,10 \%$ \\
\hline Terceira opção - Jornais e Revistas & 26 & $23,85 \%$ \\
\hline Outros & 13 & $11,93 \%$ \\
\hline Total & 109 & $100,00 \%$ \\
\hline
\end{tabular}


Pela tabela 4, verifica-se que os alunos que responderam corretamente a essas questões e encaixavam-se nos critérios informados foram I02 respondentes, que indicaram grau de conhecimento intermediário ou avançado; e, Io9 para aqueles que indicaram grau de conhecimento alto ou altíssimo. Para aqueles com grau de conhecimento intermediário para cima, a forma de atualização mais importante são os amigos e/ou parentes, seguidos de mídias sociais e jornais e revistas. Em contrapartida, para aqueles cujos graus de interesse são altos, as mídias sociais refletem maior importância, seguidas de amigos e/ ou parentes, e, por fim, jornais e revistas.

Pode-se inferir que o interesse e conhecimento sobre o tema dependem bastante da influência das pessoas conhecidas e próximas, dado que não é um tema muito disseminado ainda e que precisa de influenciadores e exemplos. Já as mídias sociais são partes importantes, dado que estão ı०\% presentes na vida dos jovens da geração $\mathrm{Y}$, maioria nesse questionário e foco do estudo.

Pelo fato de palestras dentro e fora da FEA não terem sido citadas como principais formas de atualização, infere-se que ainda faltam incentivos e eventos dentro das próprias universidades. 


\section{OPORTUNIDADES E VAGAS NA ÁREA}

Na tabela 5, observa-se que a maioria dos respondentes não buscou ou encontrou alguma oportunidade de trabalhar em um negócio social, representando mais de $84 \%$ da amostra. Entre os 65 que buscaram ou encontraram, a porcentagem mais representativa ficou entre os alunos dos segundos anos, com $15,65 \%$.

De acordo com suas respostas, observa-se que os motivos principais pelos quais os alunos responderam "não” foi “outro motivo” e por não conhecerem amigos ou parentes que já fizeram parte de um negócio social. Nesse "outro", as respostas foram convergentes a "não estou à procura de emprego", "falta de interesse", "perspectiva de carreira" e "não conheço o bastante".

Para aqueles que responderam sim, a maioria respondeu que encontrou ou buscou vagas por meio de recomendação de amigos e parentes. A opção menos votada foi a de recomendação de professores. Pode-se sugerir que isso tenha acontecido pela falha na comunicação entre corpo docente e discente, talvez, por não terem muitos professores voltados ao tema negócios sociais. O "outro" teve respostas muito diversas, como "mídias sociais", "palestras", "manilhões" e "sou cofundador". Pode-se observar com ambas as perguntas, portanto, a influência de amigos e parentes para disseminar o tema.

Observa-se que a maioria afirmou que não encontrou ou buscou vagas, mesmo tendo conhecimento intermediário e alto, ou interesse alto. Nos motivos dos primeiros, $24,59 \%$ dos respondentes afirmaram que não tiveram tempo ou que ainda não estão buscando emprego e 22,13\% estão incertos quanto ao futuro desse tipo de organização. Para aqueles cujo interesse é alto, 24,06\% responderam que não conhecem ninguém que faça ou tenha feito parte de um negócio social e 23,31\% também disseram que não têm tempo ou não estão buscando emprego. 
\& EDISON QUIRINO D'AMARIO

Tabela 5 Oportunidades e vagas (sim ou não, e motivos)

\begin{tabular}{|c|c|c|c|c|c|c|c|c|c|}
\hline \multirow{3}{*}{$\begin{array}{l}\text { Você já buscou ou } \\
\text { encontrou alguma } \\
\text { oportunidade de } \\
\text { trabalhar em um } \\
\text { negócio social? }\end{array}$} & \multicolumn{8}{|c|}{ Semestre } & \multirow[t]{3}{*}{ Total } \\
\hline & \multicolumn{2}{|l|}{$1^{\circ}$ e $2^{\circ}$} & \multicolumn{2}{|c|}{$3^{\circ}$ e $4^{\circ}$} & \multicolumn{2}{|c|}{$5^{\circ}$ e $6^{\circ}$} & \multicolumn{2}{|c|}{ Últimos } & \\
\hline & Freq. & $\%$ & Freq. & $\%$ & Fre & $\%$ & Freq. & $\%$ & \\
\hline Não & 160 & 87,43 & 97 & 84,35 & 89 & 89,90 & 90 & 86,54 & 436 \\
\hline Sim & 23 & 12,57 & 18 & 15,65 & 10 & 10,10 & 14 & 13,46 & 65 \\
\hline Total de respondentes & 183 & 100,0 & 115 & 100,0 & 99 & 100,0 & 104 & 100,00 & 501 \\
\hline
\end{tabular}

\begin{tabular}{|c|c|c|c|c|c|c|c|c|c|}
\hline \multirow[t]{3}{*}{ Respostas SIM } & \multicolumn{4}{|c|}{ Semestre } & & & & & \multirow[t]{3}{*}{ Total } \\
\hline & \multirow{2}{*}{\multicolumn{2}{|c|}{$\begin{array}{l}1^{\circ} \text { e } 2^{\circ} \\
\text { Freq. } \%\end{array}$}} & \multicolumn{2}{|c|}{$3^{\circ}$ e $4^{\circ}$} & \multicolumn{2}{|c|}{$5^{\circ}$ e $6^{\circ}$} & \multicolumn{2}{|c|}{ Últimos } & \\
\hline & & & Fre & $\%$ & Fre & $\%$ & Fre & $\%$ & \\
\hline $\begin{array}{l}\text { Site de divulgação de } \\
\text { vagas tradicionais }\end{array}$ & 5 & 16,13 & 1 & 4,55 & 3 & 18,75 & 2 & 13,33 & 11 \\
\hline $\begin{array}{l}\text { Recomendação de } \\
\text { amigos ou parentes }\end{array}$ & 13 & 41,94 & 9 & 40,91 & 5 & 31,25 & 7 & 46,67 & 34 \\
\hline $\begin{array}{l}\text { Recomendação de } \\
\text { professores da FEA }\end{array}$ & 1 & 3,23 & 0 & 0,00 & 0 & 0,00 & 0 & 0,00 & 1 \\
\hline $\begin{array}{l}\text { Próprio site da } \\
\text { organização }\end{array}$ & 6 & 19,35 & 6 & 27,27 & 4 & 25,00 & 2 & 13,33 & 18 \\
\hline Outro & 6 & 19,35 & 6 & 27,27 & 4 & 25,00 & 4 & 26,67 & 20 \\
\hline Total de respondentes & 31 & 100,0 & 22 & 100,0 & 16 & 100,0 & 15 & 100,0 & 84 \\
\hline
\end{tabular}

\begin{tabular}{|c|c|c|c|c|c|c|c|c|c|}
\hline \multirow{4}{*}{$\begin{array}{l}\text { Respostas NÃO } \\
\text { Não consegui } \\
\text { encontrar vagas/não } \\
\text { tinham vagas abertas }\end{array}$} & \multicolumn{6}{|c|}{ Semestre } & & & \multirow[t]{3}{*}{ Tota } \\
\hline & \multirow{2}{*}{\multicolumn{2}{|c|}{$\begin{array}{l}1^{\circ} \text { e } 2^{\circ} \\
\text { Freq. } \%\end{array}$}} & \multicolumn{2}{|c|}{$3^{\circ}$ e $4^{\circ}$} & \multicolumn{2}{|c|}{$5^{\circ}$ e $6^{\circ}$} & \multicolumn{2}{|c|}{ Últimos } & \\
\hline & & & Freq. & $\%$ & Freq. & $\%$ & Fre & $\%$ & \\
\hline & 12 & 6,38 & 4 & 3,67 & 11 & 9,09 & 13 & 11,82 & 40 \\
\hline Baixa remuneração & 11 & 5,85 & 14 & 12,84 & 22 & 18,18 & 28 & 25,45 & 75 \\
\hline $\begin{array}{l}\text { Não conheço nenhum } \\
\text { amigo ou parente que } \\
\text { faz/fez parte de um NS }\end{array}$ & 63 & 33,51 & 32 & 29,36 & 28 & 23,14 & 16 & 14,55 & 139 \\
\hline $\begin{array}{l}\text { Incerteza quanto ao } \\
\text { futuro desse tipo de } \\
\text { organização }\end{array}$ & 41 & 21,81 & 32 & 29,36 & 33 & 27,27 & 27 & 24,55 & 133 \\
\hline Outro & 61 & 32,45 & 27 & 24,77 & 27 & 22,31 & 26 & 23,64 & 141 \\
\hline Total de respondentes & 188 & 100,0 & 109 & 100,0 & 121 & 100,0 & 110 & 100,0 & 528 \\
\hline
\end{tabular}




\section{ENTIDADES E MOVIMENTOS ESTUDANTIS}

Em relação a conhecer as entidades e os movimentos estudantis, considerando todas as respostas, 90,68\% conhecem a FEA Social, 32,82\% o CHOICE, Io,68\% o ChangeMaker, 4,47\% o MakeSense e, por fim, I9,6r\% o Yunus.

Esses números são bem expressivos e apontam que, apesar de a maioria dos alunos não conhecer Ioo\% os negócios sociais, eles são familiarizados com os movimentos que acontecem a sua volta.

Ao restringir o estudo para aqueles cujos conhecimentos e interesses são altos, observam-se números bem diferentes desses já apresentados:

a. Conhecimento Alto: 91,49\% conhecem a FEA Social, 59,57\% o CHOICE, 26,95\% o ChangeMaker, 7,09\% o MakeSense e 43,26\% o Yunus.

b. Interesse Alto: 90,73\% conhecem a FEA Social, 52,98\% o CHOICE, $22,52 \%$ o ChangeMaker, 6,62\% o MakeSense e 33,II\% o Yunus.

Dessa maneira, deduz-se que quanto maior o conhecimento e maior o interesse, os alunos tendem a conhecer mais sobre movimentos que estão presentes no campus da FEA-USP, como, por exemplo, o ChangeMaker, que é uma comunidade global on-line que incentiva e apoia indivíduos no seu papel de agente de mudança por meio da inspiração, orientação e colaboração com outros membros da comunidade que estão em diversos estágios do ciclo do "ato da mudança”; e o MakeSense, que é um projeto que surgiu na França com o intuito de conectar empreendedores sociais para juntos resolverem desafios. Embora esses dois movimentos não estejam constantemente fazendo palestras ou propagandas dentro da faculdade, eles são conhecidos. 


\section{DESAFIOS}

Nessa primeira parte da pesquisa foram consideradas apenas respostas completas, ou seja, daqueles alunos que numeraram de i a 8 todas as oito questões descritas, sem deixar nenhuma em branco.

Não foram consideradas as respostas daqueles que apenas numeraram os três principais desafios de negócios sociais, mas, em estudos futuros, essa análise poderá ser feita e complementada a este trabalho, dado que elas também podem indicar fatores e dados úteis e representativos.

A maioria apontou que o maior desafio dos negócios sociais é se autossustentar financeiramente, com 209 escolhas, representando 51,47\%. O segundo maior desafio, com 80 escolhas (19,70\%), foi considerado o de competir com empresas tradicionais, e o terceiro, o de conseguir financiamento, com 76 escolhas, representando $18,71 \%$ do total de respostas. O mais votado para ser o último desafio de negócios sociais foi o de medir o impacto social gerado, com I3I votos, representando $32,26 \%$.

Pode-se sugerir que os alunos, em geral, não acham que esse tipo de negócio seja rentável, não consegue ser competitivo e, portanto, tem dificuldade em atrair investidores e financiamento.

Para aqueles com conhecimento intermediário ou alto, o primeiro desafio também é autossustentar-se financeiramente, com 47,46\% das escolhas; o segundo é o de conseguir financiamento, com 28 escolhas, representando 23,73\%; e o terceiro desafio é o de remunerar adequadamente os funcionários. O mais votado para ser o último desafio foi o de medir o impacto social gerado, com 37 votos, representando 31,90\%.

Assim, é possível colocar que a visão daqueles que têm conhecimento mais alto é bem parecida com a visão geral dos alunos, dado que os dois primeiros desafios e o último foram similares e o único diferente foi o de remunerar adequadamente os funcionários. Isso pode indicar uma percepção de que, como a empresa não consegue ser rentável o suficiente para se autossustentar, ela não consegue financiamento e, portanto, não consegue remunerar os seus funcionários adequadamente. 
Entretanto, para aqueles que têm interesse alto, as respostas foram exatamente iguais às daqueles que têm conhecimento intermediário ou alto: o maior desafio dos negócios sociais é autossustentar-se, seguido de conseguir financiamento e, por fim, remunerar os funcionários. Em compensação, para eles, o menor desafio de todos é o de oferecer oportunidade de desenvolvimento para os funcionários, mostrando uma visão positiva dos negócios sociais e das experiências que os próprios colaboradores conseguem ter de aprendizado, por exemplo. 


\section{CONSIDERAÇÕES FINAIS}

Este estudo teve como objetivo principal entender melhor as percepções e os conhecimento dos alunos de administração da FEA-USP, por meio da aplicação de um questionário durante as aulas no segundo semestre de 2015.

Pôde-se observar que, com os negócios sociais, por mais que hoje se acredite que eles sejam a grande solução do esgotamento de recursos, desigualdade e até mesmo problemas mercadológicos, este tipo de empreendimento social ainda carece de maior foco de pesquisa e disseminação. Até o presente momento, observa-se um crescimento do número de start-ups e pequenas e médias empresas voltadas para a geração de valor social. No entanto a possibilidade de obtenção de escala no impacto gerado e consolidação dos modelos de negócios ainda permanece no plano da intenção de muitas iniciativas.

Por meio do levantamento realizado, foi possível observar que os alunos acreditam que conhecem bastante sobre esse tipo de negócio, todavia os resultados não sustentam esse posicionamento.

O processo de disseminação de modelos de negócios sociais ainda é lento e necessita de iniciativas e ações para conseguir gerar maiores interesses nas pessoas. A maioria dos líderes e gestores contemporâneos que já está no mercado há algum tempo, e não é tão familiarizada com o tema, pode não entender como é possível conseguir atuar na lógica do mercado e, ao mesmo tempo, fazer um bem à sociedade.

É necessária, então, uma conscientização desses atores, principalmente, daqueles que serão gestores no futuro: aos Ys, é necessário que sejam explicitados sobre a importância de se pensar em alternativas para o capitalismo, bem como apresentar resultados de pesquisas que indiquem que elas podem ser rentáveis, atrativas e competitivas, trazendo impacto e desenvolvimento social.

Em se tratando da FEA-USP, foco deste estudo, foi possível observar mais e mais iniciativas de implantar esse assunto dentro do ambiente acadêmico. Exemplos como a disciplina "Empreendedorismo Social e Responsabilidade Social", ministrada pelo terceiro ano consecutivo, durante a semana da 
pátria, e a efetivação da entidade social chamada FEA Social evidenciam essa afirmação. Também, organizações como a Artemisia, Ashoka e Vox Capital, que são especialistas no tema, fazem interações com os estudantes das faculdades.

A principal contribuição deste estudo é que se pôde observar que há uma grande demanda a ser atendida. E se isso for concretizado, as chances de consolidação dos negócios sociais aumentam. Porém a oferta ainda está tímida devido ao desconhecimento do corpo docente sobre este tipo de empreendimento, assim como faltam pesquisas mais robustas sobre tendências e perspectivas desse tipo de empreendimento. 


\section{REFERÊNCIAS}

ALSOP, R. The trophy kids grow up: how the millennial generation is shaking up the workplace. São Francisco: Jossey-Bass, 2008.

APRIGIO, B. Gerações no mercado de trabalho: Geração Y. Revista de Administração do UNISAL. Campinas, v.3, n.3, p. 19-28, jan./abr. 2013.

BARKI, E. et al. Social entrepreneurship and social business: Retrospective and prospective research. RAE-Revista de Administração de Empresas, São Paulo, v. 55, n. 4, p. 380-384, jul. 2015. Disponível em: < http:/ / rae.fgv.br/rae/vol55-num4-2015/socialentrepreneurship-and-social-business-retrospective-and-prospective-resear $>$. Acesso em: $25 / 01 / 2016$.

BORZAGA, C.; DEPEDRI, S.; GALERA, G. Interpreting social enterprises. R. Adm. Revista de Administração, São Paulo, v. 47, n. 3, p. 398-409, jul./ ago./ set. 2012.

COMINI, G.; BARKI, E.; AGUIAR, L. A three-pronged approach to social business: A Brazilian multi-case analysis. R. Adm. Revista de Administração, São Paulo, v. 47, n. 3, p. 385-397, jul./ ago./set. 2012.

COMINI, G.; TEODÓSIO, A. Inclusive business and poverty: prospects in the Brazilian context. R.Adm. Revista de Administração, São Paulo, v. 47, n. 3, p. 410-421, jul./ago./set. 2012.

DEES, J. The Meaning of Social Entrepreneurship. Boston, MA: Harvard Business School, 1998.

DRIES, N.; PEPERMANS, R.; DE KERPEL, E. Exploring four generations' beliefs about career: is "satisfied" the new "successful"? Journal of Managerial Psychology, v. 23, n. 8, p. 907-928, 2008.

DUTRA, J; NAKATA, L; VELOSO, E. Percepção sobre carreiras inteligentes: diferenças entre as gerações $\mathrm{Y}$, X e baby boomers. In: ENCONTRO ANUAL DA ASSOCIAÇÃO NACIONAL DOS PROGRAMAS DE PÓS-GRADUAÇÃO EM ADMINISTRAÇÃO, 32., 2008, Rio de Janeiro Anais... Rio de Janeiro: ANPAD, 2008. p. 89-100.

FISCHER, R. M. Negócios Sociais. In: BOULLOSA, R. F. Dicionário para a formação em gestão social. Salvador: CIAGS/UFBA, 2014. p. 125-127.

FORQUIN, J. C. Relações entre gerações e processos educativos: transmissões e transformações. In: CONGRESSO INTERNACIONAL CO-EDUCAÇÃO DE GERAÇÕES SESC, outubro de 2003, São Paulo. Anais... São Paulo, 2003. Disponível em: $<$ http: / / www.sescsp.org.br/sesc/images/upload/conferencias/83.rtf $>$. Acesso em: $19 / 01 / 2016$.

GATTI, B. A. Estudos quantitativos em educação. Educação e Pesquisa, São Paulo, v. 30, n. 1, p. 11-30, jan./abr. 2004. Disponível em: <http:/ / www.scielo.br/pdf/ep/v30n1/ a02v30n1.pdf. $>$ Acesso em: 18/10/2015. 
KUPPERSCHMIDT, B. R. . Multigenerational employees: Strategies for effective management. The Health Care Manager, v. 19, n. 1, p. 65-76. 2000.

LAKATOS, E. M; MARCONI, M. A. Fundamentos de metodologia científica. São Paulo: Atlas, 1985.

PHILLL S, J.; DEIGLMEIER, K.; MILL ER, D. Rediscovering social innovation. Stanford Social Innovation Review, Stanford, v. 6, n. 4, p. 34-43, Maio 2008.

PORTER, M. E.; KRAMER M. A Grande Ideia: Criação de valor compartilhado. Harvard Business Review, Boston, v. 13, n. 3, p. 72-91, jul./ set. 2011.

SANTANA, A; SOUZA, L.. Empreendedorismo com foco em negócios sociais. Curitiba: NITS UFPR, 2015.

SÁ, P.; LEMOS, A.; CAVAZZOTE, F. Expectativas de Carreira na Contemporaneidade: O que Querem os Jovens Profissionais? Revista ADM.MADE, Rio de Janeiro, ano 14, v. 18, n. 2, p. 8-27, mai./ago. 2014.

SAMPIERI, R. H. et al. Metodologia de pesquisa. 3. ed. São Paulo: McGraw-Hill, 2006.

SILVA, R. B. P. Relatório Final PIBIC - Mapeamento dos desafios encontrados pelos negócios sociais no Brasil. 2013. Disponível em: <http://gvpesquisa.fgv.br/sites/ gvpesquisa.fgv.br/files/publicacoes/mapeamento_dos_desafios_frequentemente_ encontrados pelos empreendimentos sociais no brasil.pdf $>$. Acesso em: 15/10/2015.

SOUZA, A. N. L. Globalização: origem e evolução. Caderno de Estudos Ciência e Empresa, Teresina, Ano 8, n. 1, jul. 2011. Disponível em: $<$ http: / / www.faete.edu.br/revista/ Artigo\%20Andreia\%20Nadia\%20Globalizacao\%20ABNT.pdf > Acesso em: 15/10/2015.

UNILEVER FOUNDATION. Disponível em:< https:/ / www.unilever.com.br/about/ investimento-social >. Acesso em: 15/10/2015.

VELOSO, E. É possível negar a geração Y no Brasil? Salvador, v.19 - n.62, p. 745-747 - Jul./ Set. -2012 .

YUNUS, M. Creating a world without poverty: social business and the future of capitalism. New York: Public Affairs, 2007.

YUNUS, M.; MOINGEON, B.; LEHMANN-ORTEGA, L. Building Social Business Models: Lessons from the Grameen Experience. HEC PARIS - Working paper, v. 913, Fev. 2009. Disponível em: $<$ http://www.hec.fr/var/corporate/storage/original/application/ 4c2fc23d0007ff24248fc6f8003d468d.pdf $>$. Acesso em: 19/10/2016. 


\title{
DADOS DOS AUTORES
}

\author{
AMANDA LEME JAHCHAN`amanda.jahchan@gmail.com \\ Bacharel em Administração pela FEA/USP \\ Instituição de vinculação: Faculdade de Economia e Administração da Universidade de \\ São Paulo \\ São Paulo/SP - Brasil \\ Áreas de interesse em pesquisa: Gestão de pessoas e Negócios Sociais. \\ * Rua Padre João Antonio, 300 Vila Maria São Paulo/SP 02119-030
}

\section{GRAZIELLA MARIA COMINI gcomini@usp.br}

Livre Docente em Gestão de Pessoas pela FEA USP

Instituição de vinculação: Faculdade de Economia e Administração da Universidade de São Paulo - Programa de Pós-Graduação

São Paulo/SP - Brasil

Áreas de interesse em pesquisa: Gestão de Pessoas, Negócios Sociais, Inovação e

Diversidade.

EDISON QUIRINO D`AMARIO edamario@uol.com.br

Doutorando Área: Gestão Humana e Social Instituição: FEA USP

Instituição de vinculação: Faculdade de Economia e Administração da Universidade de São Paulo - Programa de Pós-Graduação

São Paulo/SP - Brasil

Áreas de interesse em pesquisa: Negócios Sociais, inovação e diversidade 